\title{
EL ENCLAVE DE LOS JUICIOS DE TRANSICIÓN: OBSERVACIÓN DEL CASO BRASILEÑO ${ }^{1}$
}

\author{
THE ENCLAVE OF THE TRIALS OF TRANSITION: THE BRAZILIAN CASA OBSERVATION
}

\section{Eduardo Saad Diniz*}

\begin{abstract}
:
In this paper the author analyses the problems of the resolution of the past and the transitional justice of the Brazilian case in three different steps: (1) construction of the "identity" of the Brazilian dictatorship; (2) problems of juridification (Verrechtlichung); (3) observation of the "Guerrilha do Araguaia" and the "Amnesty Law"
\end{abstract}

Keywords: Transitional justice. Crimes of the Military Dictatorship. Amnesty Law.

Resumo:

Neste artigo o autor analisa os problemas da superação do passado e da justiça de transição no caso brasileiro em três passos distintos: (1) construção da "identidade" da ditadura brasileira; (2) problemas de juridificação (Verrechtlichung); (3) observação da Guerrilha do Araguaia e Lei da Anistia.

Palavras-chaves: Justiça de transição. Crimes da Ditadura Militar. Lei de Anistia.

1. Presentación del problema: superación del pasado mediante el derecho

Empezando por el hecho de que las propias normativas de las Naciones Unidas permitieron a cada uno de los países poder elegir el modelo adecuado para su propia justicia de transición, las posibilidades de comprensión teórica de la "transición por medio del derecho" revela menos reglas de validez universal que excepciones. En Brasil hablamos de una "excepción à la brasileira" y que "ella fue la dictadura más violenta que el ciclo negro latinoamericano conoció" ${ }^{2}$ En Colombia, por su parte, Aponte Cardona trae el mismo argumento de la excepción colombiana. ${ }^{3} \mathrm{Y}$ a la experiencia argentina se

Artículo producido por ocasión del I Seminario de Justicia de Transición de la Universidad Nacional de Mar del Plata, 21-22 de febrero de 2011, revisado por Cecilia Marcela Ugartemendía y Andrés Falcone, con mis agradecimientos. Las citas en otros idiomas fueron traducidas libremente por nosotros.

Doctor en Derecho por la Universidad de São Paulo, Brasil. Fue Becario DAAD/Capes en la Universität Regensburg, Alemania.

2 TELES, Édson; SAFATLE, Vladimir. Apresentação. In: TELES, Édson; SAFATLE, Vladimir (Org.). O que resta da ditadura: a exceção brasileira. São Paulo: Boitempo, 2010. p. 9; SAFATLE, Vladimir. Do uso da violência contra o Estado ilegal. In: TELES, Édson; SAFATLE, Vladimir (Org.). O que resta da ditadura: a exceção brasileira. São Paulo: Boitempo, 2010. p. 250 y ss.

3 APONTE CARDONA, Alejandro. La Colombia: un caso sui generis nell'ambito della giustizia di transizione. In: FRONZA, Emanuela; FORNASARI, Gabriele (Org.). Il superamento del passato e il superamento del 
refieren como "verdadero y propio laboratorio de justicia penal internacional"4 con sus juicios por la verdad. ${ }^{5}$ La historia de las dictaduras latinoamericanas evidencia una serie de especificaciones y en cada especificación se encuentra un momento determinado del proceso real. El esfuerzo de comprensión de una teoría puede solamente ser el de demostrar las leyes generales del movimiento teórico-conceptual, cuya demostración aprehende el sentido de cada una de las manifestaciones de los casos en observación. Aquí se trata, entonces, de aprehender las relaciones generales entre las experiencias concretas, que de experiencias dictatoriales se tratan, pero guardando la identidad que le permite conocer el sentido y conducir la resolución de su "verdad" El proceso de realización de la identidad dictatorial es tomado en su evolución histórica de sentido, en el cuestionamiento de la identidad del problema, luego de que se elaboran funcionalmente sus aspectos formalesprocedimentales y su configuración institucional, para, al cabo de eso, extraer las ideas (y criterios) que diferencian su racionalidad jurídica de la Historia.

Hablo del esclarecimiento de los atributos particulares de una teoría (sobre las posibilidades) del conocimiento de la verdad mediante el derecho penal, cuya problematización será orientada por la necesidad de fundamentación empírica de las universalidades abstractas que interfieren en los procesos de imputación justo/injusto. Quiero decir, solamente bajo las determinaciones concretas del caso brasileño se justifica cómo y en qué medida puede - o no - el derecho posibilitar la creación de espacios de libre realización del individuo para el conocimiento de la verdad.

O sea, conocer las especificaciones concretas de una experiencia permiten pensar el problema en toda su extensión: investigar si es posible concebir un juicio de validez universal sobre la superación histórica del pasado mediante el derecho. Aun más específicamente, el problema que se nos presenta es el sentido de la verdad en Historia. La concepción de la memoria sobre la experiencia dictatorial brasileña, así como en la especulación hermenéutica elaborada por Paul Ricoeur, se deja orientar por la idea de la reconstrucción del sentido simbólico objetivado en nuestra sociedad, a la vez que su reverso, la fragmentación, significa la dispersión del recuerdo y configura el sentimiento de culpa. ${ }^{6}$

presente: la punizione delle violazioni sistematiche dei diritti umani nell'esperienza argentina e colombiana. Trento: Universitá degli Studi di Trento, 2009. p. 177 y ss.

$4 \quad$ FRONZA, Emanuela; FORNASARI, Gabriele. Premessa. In: FRONZA, Emanuela; FORNASARI, Gabriele (org.) Il superamento del passato e il superamento del presente: la punizione delle violazioni sistematiche dei diritti umani nell'esperienza argentina e colombiana. Trento: Universitá degli Studi di Trento, 2009 . p. 6.

5 Sosteniendo objeciones analíticas de naturaleza "teleológica", "epistemológica", "metodológica", "técnica", "política" y "histórica" a esos juicios por la verdad, PASTOR, Daniel. Processi penali solo per conoscere la verità? L'esperienza argentina. In: FRONZA, Emanuela; FORNASARI, Gabriele (Org.) Il superamento del passato e il superamento del presente: la punizione delle violazioni sistematiche dei diritti umani nell'esperienza argentina e colombiana. Trento: Universitá degli Studi di Trento, 2009. p. 124-156.

6 RICOEUR, Paul. La mémoire, I'historie, l'oubli. Paris: Éditions du Seuil, 2000. p. 598-599. Desde una perspectiva de la poética de la história, WHITE, Hayden. Meta-história. São Paulo: Edusp, 1995. La cuestión de la culpa ocupa espacio privilegiado en el debate filosófico: JASPERS, Karl. Die Schuldfrage. 
Así que el sentido de la memoria para el derecho consiste en un juicio. ${ }^{7}$ Una valoración que debe orientar el juicio de transición, más ampliamente considerado. ${ }^{8}$ Sobretodo si ese pasado es el pasado de la institución represora DOPS-DOI/CODI, una máquina del Estado brasileño de producción de atrocidades del tipo tortura, ${ }^{9}$ desaparición forzada de integrante ${ }^{10}$ de la resistencia armada a la dictadura, muerte y o mismo persecución asesina de aquellos que se oponían al régimen.

Esta ponencia es una primera aproximación al tema, sin mayores precisiones bibliográficas o incursiones en el derecho comparado. ${ }^{11}$ Será esquematizada de la forma siguiente: luego de la (1) presentación del problema (qué puede hacer la racionalidad jurídico-penal frente a los juicios de transición?), serán desarrolladas las líneas rectoras del (2) autoritarismo à la brasileira y la especificación de la "identidad institucional" brasileña. Más allá de eso, serán expuestos (3) los enclaves inmanentes a los límites

Zurich: Artemis, 1946; ARENDT, Hannah. Eichmann em Jerusalém: um relato sobre a banalidade do mal. Trad. José Rubens Siqueira. 4. reimp. São Paulo: Cia. das Letras, 1999; KODALLE, Klaus M. Verzeihung nach Wendezeiten? Jenaer Philosophische Vorträge und Studien, Erlangen, v. 12, 1994.

7 El poder de juzgar está en el centro de la argumentación de Hannah Arendt para la determinación del ámbito de la responsabilidad personal y colectiva, ARENDT, Hannah. Responsibility and Judgement. New York: Schocken Books, 2003. p. 22.

8 Basándose fundamentalmente en la experiencia del Internacional Center for Transitional Justice (ICTJ), Mezarobba delimita los deberes del Estado frente a las víctimas y a la sociedad: (1) derecho a la justicia (con procedimientos locales, internacionales o híbridos); (2) derecho a la verdad (incluyendo la especificación de los delitos y la formación de comisiones); (3) derecho a la compensación (reparaciones y restituciones simbólicas) - como el registro del luto respeto a los muertos y desaparecidos, SOARES, Inês Virgínia Prado. Memoria democrática e desaparecidos políticos. In: SOARES, Inês Virgínia Prado (Org.). Memória e verdade: a justiça de transição no Estado democrático brasileiro. Belo Horizonte: Ed. Fórum, 2009. p. 335 -; (4) derecho a accountability (reformas institucionales, con el alejamiento de los agentes públicos irresponsables, extendiéndose a una reforma del Judiciario), MEZAROBBA, Glenda. O que é justiça de transição? Uma análise do conceito a partir do caso brasileiro. In: SOARES, Inês Virgínia Prado (Org.). Memória e verdade: a justiça de transição no Estado democrático brasileiro. Belo Horizonte: Ed. Fórum, 2009. p. 43-44.

, Sobre la tortura en Brasil, véase ALARCON, Rodrigo. Brasil: represión y tortura. Santiago de Chile: Editorial Orbe, 1971; FON, Antonio Carlos. Tortura: a história da repressão política no Brasil. São Paulo, 1979; JORDÃO, Fernando. Dossiê Herzog: prisão, tortura e morte no Brasil. 2. ed. São Paulo: Global, 1979.

10 PERRUSO, Camila Akemi. O desaparecimento forçado de pessoas no sistema interamericano de direitos humanos: direitos humanos e memória. 2010. 222f. Tese (Doutorado)-Faculdade de Direito, Universidade de São Paulo, São Paulo, 2010.

Ejemplifico con AMBOS, Kai. De la estructura 'jurídica' de la represión y de la superación del pasado en Argentina mediante el derecho penal: un comentario desde el punto de vista jurídico. Revista de Ciencias Penales, Montevideo, n. 3, p. 21-35, 1997; reciente, la manifestación en contra de EIROA, Pablo. Justicia, reconciliación y paz. Si y por qué castigar por medio de tribunales internacionales. In: PASTOR, Daniel R.; GUZMÁN, Nicolás (Org.). Problemas actuales de la Parte General del Derecho Penal. Buenos Aires, 2010, p. 757; KIM, Young Whan. Vergangenheitsbewaltigung durch das Strafrecht? Archiv fur Rechts und Sozialphilosophie, n. 4, v. 84, p. 505-516, 1998. p. 505-516; FALCONE, Andrés. Superação do Passado Alemão pelo Direito Penal: Reflexões sobre os Vinte Anos da Queda do Muro de Berlim. Trad. Eduardo Saad Diniz. In: Editora Magister, 07.01.2011, disponible en: <http://www.editoramagister.com/doutrina ler.php?id $=902>$. Aceso en: 07 jan. 2011. Aún, la relevante discusión aportada sobre el caso surafricano en LOLLINI, Andrea. Costituzionalismo e giustizia di transizione: il ruolo costituente della Comissione sudafricana verità e riconciliazione. Bologna: Il Mulino, 2005. 
de la juridificación (Verrechtlichung) de los juicios de transición, seguidos de la (4) observación del caso brasileño (Informe del Araguaia y la cuestión de la Ley de Amnistía y la necesidad de autorizar jurídicamente el acceso a los archivos históricos). Entonces, luego del levantamiento histórico habrá una elaboración funcional del tema, seguida de los problemas de legitimación y de la fundamentación racional de los juicios contra el totalitarismo. Al cabo de eso se propondrá una mirada a la superación del presente en Brasil, cuyos niveles de consciencia de la libertad padecen, todavía, de una sufrible insuficiencia, bien lejos de lo que representó el juicio de Nürnberg para la consolidación de una consciencia jurídica y para la juridificación de un orden penal internacional ${ }^{12}$. Bajo esa insuficiencia, la experiencia brasileña de auto-comprensión del autoritarismo aún navega desanclada y sin apuntar una resolución racional para el dilema de la superación: si puede el derecho penal, para hacer justicia contra las dictaduras, inducir con sus procedimientos la suprasunción de las experiencias dictatoriales latinoamericanas bajo la memoria universal de totalitarismo; y ahí sí, si ese movimiento conceptual ofrecería la potencia de efectiva realización de prácticas de subjetivación, más afectadas a la constitución moral emancipadora de los individuos.

2. El autoritarismo à la brasileira: la actualidad de las estructuras dictatoriales

Desde los años 30, Brasil vivenció una genuina "confusión ideológica" marcada por una "falta de orientación de los elementos que personificaban las fuerzas dirigentes de la política nacional" 13 incluso por la profusión de fuentes históricas que dificultan la aprehensión de una síntesis definitiva del pensamiento vigente en esa época. ${ }^{14}$ Nuestra historia fue expresión de la inviabilidad de acceder a una explicación universal del fenómeno genéricamente concebido como "dictadura" Buscando una síntesis, con René Dreifuss, "el sistema político imperante y las clases dominantes en su conjunto enfrentaban una crisis básica" 15 a tal punto de "fragilidad política e ideológica" que se implantó una percepción de "serio potencial de amenaza, suficientemente severo para

12 LAFER, Celso. A reconstrução histórica dos direitos humanos: um diálogo com o pensamento de Hannah Arendt. 5. reimpr. São Paulo: Cia. das Letras, 1998. p. 169.

13 AMARAL, Azevedo. O Estado autoritário e a realidade nacional. Rio de Janeiro: José Olympio, 1938. v. 1.p. 139.

14 El intento de establecer aspectos de comprensión del "estado burocrático-autoritário", O'DONNELL, Guillermo. Reflexões sobre os estados burocrático-autoritários. São Paulo: Vértice, 1987. p. 36 y ss.; Para un estudo de los orígenes históricos, ROUQUIÉ, Alain. O Estado militar na América Latina. Trad. Leda Rita Cintra Ferraz. São Paulo: Alfa-Ômega, 1982. p. 31 y ss.; el abordaje original del carácter multifacetado de la dictadura RAGO FILHO, Antonio. Ideologia 64. 1998. 68f. Tese (Doutorado)-Pontificia Universidade Católica de São Paulo, São Paulo, 1998.

is DREIFUSS, René Armand. 1964: a conquista do Estado, ação política, poder e golpe de classe. 2. ed. Rio de Janeiro: Petrópolis, 1981. p. 140. 
reunir la burguesía en una acción agresiva, o como ellos calificaron, golpe defensivo" 16 Esas indefiniciones llevaban al descrédito del Gobierno democrático de Jango en todo el espectro político. ${ }^{17}$ El Supremo Tribunal Federal - STF - experimentó la misma fragilidad y los mismos síntomas de inestabilidad del comportamiento decisorio, con una actuación nada harmónica y poco coherente en el ámbito de los delitos políticos. ${ }^{18}$ Aún así, a los fines de la ponencia, y para guidar mínimamente mis observaciones evidenciándoles a los "enclaves" que ahora traigo para su apreciación, podríamos asumir un concepto más genérico de totalitarismo, como el que reconoce formaciones político-partidarias monopolizadas por el Estado (Franz Neumann, ${ }^{19}$ acompañada de elementos de dominación total (Hannah Arend $^{20}$ ) y concentración monopolista de los procesos decisorios.

Buscando el monopolio del comportamiento decisorio en el País, se armó todo el montaje del Golpe del 64, bajo la dirección de organizaciones derechistas de la Marcha da Familia com Deus pela Liberdade ("Marcha de la Familia con Dios por la Libertad") y la clase media avala la instauración del régimen militar. ${ }^{21}$ Desde entonces, lo que pasó fue una sucesión de manipulaciones de las esferas institucionales en Brasil, ${ }^{22}$ por cuenta de la preocupación de los militares contra las reformas sociales, ${ }^{23}$ "la sumisión de la cuestión social a la manutención del orden era un aspecto común a toda la derecha militar. Se trataba de crear con urgencia mecanismos de cohesión que evitasen el rompimiento del tejido social. Cabía instalar un sistema de protección cuyo objetivo principal era asegurar la capacidad de lucha, por medio del fortalecimiento de la estructura social y de la integración de los grupos que la componían. La integración social tenía una

16 DREIFUSS, René Armand. 1964: a conquista do Estado, ação política, poder e golpe de classe. 2. ed. Rio de Janeiro: Petrópolis, 1981. p. 140.

17 Incluso por el malogro del "Plano Trienal" del Ministro del Planeamiento, Celso Furtado, cuyo modelo desarrollista sufrió críticas tanto derechistas como izquierdistas.

18 Más sobre la posición del STF en la dictadura militar, VALÉRIO, Otávio Lucas. A toga e a farda: o Supremo Tribunal Federal e o regime militar. 2010. 222f. Dissertação (Mestrado)-Faculdade de Direito, Universidade de São Paulo, São Paulo, 2010; ALMEIDA, Frederico Normanha Ribeiro. A nobreza togada: elites jurídicas e política da administração da justiça no Brasil. 2006. 329f. Tese (Doutorado)-Faculdade de Filosofia, Letras e Ciências Humanas, Universidade de São Paulo, São Paulo, 2006; VALE, Osvaldo Trigueiro do. O Supremo Tribunal Federal e a instabilidade político-institucional. Rio de Janeiro: Civilização Brasileira, 1976.

19 NEUMANN, Franz. Democratic and authoritarian state: essays in political and legal theory. New York: The Free Press, 1957. Bajo otros criterios de comprensión, SCHMITT, Carl. Die Diktatur: von den Anfängen des modernen Souveränitätsgedankens bis zum proletarischen Klassenkampf. 7. ed. Berlin: Duncker \& Humblot, 2006.

20 ARENDT, Hannah. The origins of totalitarism. San Diego: Harvest Book, 1976.

${ }^{21}$ Véase la particular narrativa histórica de GORENDER, Jacob. No $40^{\circ}$ triste aniversário do triste evento de 1964: o golpismo contra a História. Margem Esquerda: Ensaios Marxistas, São Paulo, n. 3, 2004. p. 40-42.

22 En importante estudio historiográfico, M. H. M. Alves comprende analíticamente la historia de la dictadura en "tres ciclos de liberalización", ALVES, Maria Helena Moreira. Estado e oposição no Brasil (1964-1984). São Paulo: Edusc, 2005.

23 MENDES, Ricardo Antonio Souza. Anti-reformismo e a questão social no Brasil: o golpe de 1964. In: FREIXO, Adriano de; MUNTEAL FILHO, Oswaldo (Org.). A ditadura em debate: Estado e sociedade nos anos do autoritarismo. Rio de Janeiro: Contraponto, 2005. p. 53. 
importancia básica, y la cuestión que se colocaba era entre desarrollo o anarquía", además de la "propagación soviética en Latinoamérica por medio de la guerra revolucionaria" ${ }^{24}$ La gestión de ese medio introdujo y permitió la ascensión de la doctrina de la seguridad nacional ${ }^{25}$ entre nosotros (véase la monstruosa Operación $\operatorname{Condor}^{26}$ ), con fuerte adhesión de la propaganda nacionalista (Brasil: ame-o ou deixe-o - "Brasil: amalo o déjalo") y el apoyo de la Iglesia ${ }^{27}$ y la prensa. ${ }^{28}$

Pero el esclarecimiento del problema no se limita a la comprensión de las relaciones de poder político. Más allá de eso, la opción por la concentración decisoria y por el dominio del funcionamiento de nuestras instituciones bajo una "dictadura" fue la salida estimulada por las elites nacionales para la integración de la economía brasileña a la agenda económica global, cuya combinación sintetizó, así como dijo Coggiola, "el mercado común del terror": "durante los largos años en que perduraron las dictaduras militares, la forma principal del mecanismo de dominación política fue la unión personal de los representantes del grande empresariado con la camada superior de la burocracia estatal, con la cúpula de las Fuerzas Armadas y con los ‘sucesivos' equipos técnico-

24 MENDES, Ricardo Antonio Souza. Anti-reformismo e a questão social no Brasil: o golpe de 1964. In: FREIXO, Adriano de; MUNTEAL FILHO, Oswaldo (Org.). A ditadura em debate: Estado e sociedade nos anos do autoritarismo. Rio de Janeiro: Contraponto, 2005. p. 52.

25 COMBLIN, Joseph. A ideologia da segurança nacional: o poder militar na América Latina. 3. ed. Rio de Janeiro: CIV Brasileira, 1980; ROCHA, Maria Selma de Moraes. A evolução dos conceitos da doutrina da segurança nacional da escola superior de guerra nos anos 70. 1996. 177f. Dissertação (Mestrado)Faculdade de Filosofia, Letras e Ciências Humanas, Universidade de São Paulo, São Paulo.

26 John Dinges destaca la responsabilidad del Estado estadounidense por las atrocidades de las dictaduras latinoamericanas y por el dicado de leyes de amnistía, DINGES, John. Os anos do Condor: uma década de terrorismo no Cone Sul. Trad. Rosaura Eichenberg. São Paulo: Cia. das Letras, 2005. p. 330 e ss.; na literatura brasileira, CERVEIRA, Neusah Maria. Memória da dor: a Operação Condor no Brasil (19731985). São Paulo. 227f. Tese (Doutorado)-Faculdade de Filosofia, Letras e Ciências Humanas, Universidade de São Paulo, São Paulo, 2007. p. 43 e ss.; observando la Operación Condor desde el Archivo del Horror, SANTOS, Maria Guena dos. Operação Condor: uma conexão entre as políticas do Cone Sul da América Latina, em particular Brasil e Paraguai, durante a década de 70. 1998. 2v. Dissertação (Mestrado)-Faculdade de Filosofia, Letras e Ciências Humanas, Universidade de São Paulo, São Paulo, 1998. p. 125 e ss.

27 Especificando la relación entre Iglesia y política, en la cual se condenan los vínculos entre ellos en el ámbito "técnico-político", LLANO CIFUENTES, Rafael. Relações entre a Igreja e o Estado: a Igreja e o Estado à luz do Vaticano II, do código de direito canônico de 1983 e da Constituição brasileira de 1988. 2. ed. Rio de Janeiro: José Olympio, 1989. p. 308 y ss. Hablando de una "dupla revolución" entre las Fuerzas Armadas y la Iglesia en el Golpe de 64, pero también del rol de resistencia y lucha por los derechos humanos, SEBRIN, Kenneth P. Diálogos na sombra: bispos e militares, tortura e justiça social na ditadura. Trad. Carlos Eduardo Lins e Silva. São Paulo: Cia. das Letras, 2001. Sobre la persecución de la Iglesia por el autoritarismo, CASTRO, Marcos de. A Igreja e o autoritarismo. Rio de Janeiro: Zahar, 1985. Observando la posición "plural" de los evangélicos, SANTOS, Lyndon de Araújo. O púlpito, a praça e o palanque: os evangélicos e o regime militar brasileiro. In: FREIXO, Adriano de; MUNTEAL FILHO, Oswaldo (Org.). A ditadura em debate: Estado e sociedade nos anos do autoritarismo. Rio de Janeiro: Contraponto, 2005. p. 152 y ss.

28 Impactante, KUSHNIR, Beatriz. Cães de guarda: jornalistas e censores, do Al-5 à Constituição de 1988. São Paulo: Boitempo, 2004; en el mismo sentido, analisando la ambiguedad de la prensa (Brasil grande, con el milagre econômico versus el Brasil pequeño, cúmplice de la tortura), AGUIAR, Flávio Wolf de. A tesoura e o quadro: uma visão sobre a censura à imprensa durante o regime de 1964. Margem Esquerda: Ensaios Marxistas, São Paulo, n. 3, p. 43-47, 2004. 
gubernamentales" ${ }^{29}$ Fue instaurado por los militares un modelo desarrollista de fuerte concentración de capitales y represión de los movimientos sociales, con la finalidad de "preparar" la plataforma de crecimiento de sectores del País - energía, siderurgia, petróleo -, permitiendo al País experimentar la euforia de la "expansión capitalista", ${ }^{30}$ lo que la historiografía tradicional llamó "el milagro brasileño", consagrado al final por la conquista de la Jules Rimet por "la selección del 70, Pelé \& Co" La verdad es que no acaeció una substitución de "una autoridad política por otra autoridad política" pero sí un traslado "a la determinación para el orden del mercado" ${ }^{31}$ Hubo un acoplamiento de las políticas militares al comportamiento económico nacional, ${ }^{32}$ al punto de, por medio de la violencia militar, garantizar el proyecto económico del país, generando una especie de financierización de la violencia militar.

Así se consolida la identidad institucional del Estado brasileño, derivando de ahí las leyes represivas, los temibles "actos institucionales" de supresión de derechos, y la "Lei da segurança nacional" (Ley n. 898/1969), instrumentos jurídicos que marcan la legalidad de la ofensiva del Estado. ${ }^{33}$ Figuras como Francisco Campos (responsable por la redacción de los códigos penal y procesal penal brasileños hasta hoy en vigor) o Golbery Couto e Silva ocuparon los roles de protagonistas de esa institucionalización de la violencia, para la "acción persuasiva y de neutralización de los descontentamientos sociales" ${ }^{44}$ como ejemplo puedo mencionar el SNI, Serviço Nacional de Informações

29 COGGIOLA, Osvaldo. Governos militares na América Latina: a era das ditaduras Chile, Argentina e Brasil, luta armada e repressão. São Paulo: Contexto, 2001. p. 51.

30 Más sobre, SENRA, Álvaro de Oliveira. Após Geisel: crise do desenvolvimentismo e afirmação do neoliberalismo no Brasil. In: FREIXO, Adriano de; MUNTEAL FILHO, Oswaldo (Org.). A ditadura em debate: Estado e sociedade nos anos do autoritarismo. Rio de Janeiro: Contraponto, 2005. p. 186 e ss.

31 LECHNER, Norberto apud COGGIOLA, Osvaldo. Governos militares na América Latina: a era das ditaduras Chile, Argentina e Brasil, luta armada e repressão. São Paulo: Contexto, 2001. p. 51.

32 Los vínculos entre política, economía y ejercicio de la violencia militar parecen todavía bastante actuales, véase la crítica de Luc Mampaey y Claude Serfati contra esa financierización del poder militar impuesto por la doctrina estadunidense de seguridad nacional: "Despues de las guerras de Afganistán y Irak, los 'mercados' norte-americanos están, quizás, empezando a 'internalizar' en sus comportamientos la fatalidad de nuevas guerras y de las operaciones militares, a forjar algún tipo de compromiso 'guerra sin límites', en que la utilización discricionaria de la fuerza armada de los Estados Unidos constituye su nuevo horizonte", MAMPAEY, Luc; SERFATI, Claude. Os grupos financeiros armamentistas e os mercados financeiros: rumo a um compromisso 'guerra sem limites'? In: CHESNAIS, François (Org.). A finança mundializada. São Paulo: Boitempo, 2005. p. 247. En el mismo sentido, el valioso trabajo de UESSLER, Rolf. A guerra como prestação de serviços: a destruição da democracia pelas empresas. Rio de Janeiro: Estação Liberdade, 2008.

33 En detalles, FERNANDES, Antonio de Pádua. A produção legal da ilegalidade: os direitos humanos e a cultura jurídica brasileira. 2005. 220f. Tese (Doutorado)-Faculdade de Direito, Universidade de São Paulo, São Paulo, 2005. La investigación de la ofensiva estatal, ALVES, Maria Helena Moreira. Estado e oposição no Brasil (1964-1984). São Paulo: Edusc, 2005. p. 137 y ss.

34 PADRÓS, Enrique Serra. Repressão e violência: segurança nacional e terror de Estado nas ditaduras latinoamericanas. In: FICO, Carlos et al. (Org.). Ditadura e democracia na América Latina: balanço histórico e perspectivas. Rio de Janeiro: FGV Editora, 2008. p. 153. 
(Servicio Nacional de Informaciones) ${ }^{35}$ que transmitía el recado a los "escuadrones de la muerte"

Para la manutención de ese aparato estatal, las instituciones, incluso, se organizaron bajo la idea rectora de centralización de la violencia de Estado para promover una violenta intensificación de las asimetrías sociales, profundizada por la modernización tecnológica reaccíonaria:"36 "el progreso en la tecnología de los armamentos y el perfeccionamiento de los recursos militares concedieron a las fuerzas armadas mayor confianza en su superioridad sobre los civiles, llevándoles a hesitar menos en usar esa superioridad con objetivos políticos. ${ }^{37} \mathrm{La}$ organización institucional logró manipular el sentido simbólico de la gestión del miedo para mitigar las fuerzas del espíritu humano, reduciendo a las personas a su capacidad de rendimiento funcional al sistema dictatorial por medio de frecuentes prácticas de pérdida de la subjetividad; en lugar de conducir el ambiente normativo hacia la libre determinación de los individuos, el derecho comunicó disminución de los espacios de subjetivación y represión de los sujetos que se oponen al Estado autoritario. ¿Qué otra cosa entonces sería la tortura, sino la degradación de la subjetividad ${ }^{38}$ ¿Aún peor, qué se podría decir sobre la desaparición de las personas, sino que les es borrada la subjetividad?

En un largo proceso histórico de poco más de dos décadas, la crisis y las insuficiencias frente a la dinámica del sistema productivo mundial derribaron el régimen; las mismas elites que capitanearon el Golpe, lideraron la "liberalización" determinando la reorganización de la racionalidad económica capitalista y la restructuración de las relaciones labores en nivel internacional, por al avance tecnológico o por las medidas de expansión global del modelo de gestión e intervención del Estado en las políticas de reglamentación de la economía así llamada "neoliberal" ${ }^{39}$ En casos como el argentino y el brasileño y otros en Latinoamérica, como el mexicano, los modelos de desarrollo bajo la burocracia militar ya no se sostienen frente a la dinámica global del capital, sometidos a la "liberalización" ${ }^{40} \mathrm{Y}$ a eso llama la historiografía tradicional de transición lenta, gradual y segura.

35 LAGOA, Ana. SNI, como nasceu, como funciona. São Paulo: Brasiliense, 1983.

36 PYE, Lucien W. Os exércitos e o processo de modernização política. In: LIEUWEN, Edwin et al. (Org.). Militarismo e politica na América Latina. Rio de Janeiro: Zahar, 1964. p. 102 y ss.

37 LIEUWEN, Edwin. Militarismo e política na América Latina. In: LIEUWEN, Edwin et al. (Org.). Militarismo e política na América Latina. Rio de Janeiro: Zahar Editores, 1964. p. 59 y ss.

38 Aunque que en el pensamiento juridico-penal actual la tortura reciba una comprensión cualitativamente distinta de las prácticas acá combatidas, véase MERKEL, Reinhard. Folter und Notwehr. In: PAWLIK, Michael; ZACZYK, Rainer (Org.). Festschrift für Günther Jakobs zum 70. Geburtstag: C. Heymanns, 2007. p. 375 y ss.

39 SENRA, Álvaro de Oliveira. Após Geisel: crise do desenvolvimentismo e afirmação do neoliberalismo no Brasil. In: FREIXO, Adriano de; MUNTEAL FILHO, Oswaldo (Org.). A ditadura em debate: Estado e sociedade nos anos do autoritarismo. Rio de Janeiro: Contraponto, 2005. p. 192 y ss.

40 L. Martins llega a defender que esa "liberalización" fue "autopromovida por el régimen autoritario brasileño, 
La observación del caso brasileño nos lleva, necesariamente, a la observación del perfil institucional de Brasil, qué queda de la dictadura infiltrado en nuestra Constitución, en prescripciones "constitucionales no-liberales ('iliberales')", tal cual el artículo 142, sobre las Fuerzas Armadas - que defienden la patria y garantizan los poderes constitucionales - y el carácter del concentración del control ostensivo de Policía Militar en detrimento de la Policía Civil. ${ }^{41}$ Bajo influencia del publicista alemán Otto Mayer, Bercovici elabora estudio esclarecedor sobre las condiciones estructurales de la "presencia" dictatorial en el derecho brasileño: "el derecho constitucional pasa, el derecho administrativo permanece: la persistencia de la estructura administrativa de $1967 ",{ }^{42}$ sosteniendo la crítica a la implementación de medidas de reforma de la burocracia estatal en la dictadura con vistas a "recuperar la economía de mercado" ${ }^{43} Y$ yo ni siquiera les conté que el Código Penal Militar (Decreto-Ley 1.001/1969) brasileño de 1969 está en vigor hasta los días actuales. Fue en ese contexto que se concedió, en 1979, la "amplia, general e irrestricta" amnistía en Brasil.

3. La observación del caso brasileño (Informe Araguaia) y la cuestión de la Ley de Amnistía (Ley n. 6.683/79)

Tergiversaciones a parte, el hecho es que Brasil, en sus especificaciones, rechazó a la aplicación de la Ley de Amnistía. Asumió el sentido normativo de generalización de una negociación ${ }^{44}$ del consenso entre las fuerzas populares, "un mal

evaluando la capacidad que los militares tuvieron de controlar su propia mudanza y conducir la transición en su articulación con la sociedad, MARTINS, Luciano. A "liberalização" do regime autoritário no Brasil. In: O'DONNELL, Guillermo et al. (Org.). Transições do regime autoritário: América Latina. São Paulo: Vértice, 1988. p. 109 y ss.; en sentido semejante sobre la experiencia argentina, SANCINETTI, Marcelo. Derechos humanos en la Argentina postdictatorial. Buenos Aires: Lerner Editores Asociados, 1998. p. 11 y ss.

4i Fundamental, ZAVERUCHA, Jorge. Relações Civil-Militares: o legado autoritário da constituição brasileira de 1988. In: TELES, Édson; SAFATLE, Vladimir (Org.). O que resta da ditadura: a exceção brasileira. São Paulo: Boitempo, 2010. p. 57.

42 "Verfassungsrecht vergeht, Verwaltungsrecht besteht" BERCOVICI, Gilberto. O direito constitucional passa, o direito administrativo permanece: a persistência da estrutura administrativa de 1967. In: TELES, Édson; SAFATLE, Vladimir (Org.). O que resta da ditadura: a exceção brasileira. São Paulo: Boitempo, 2010. p. 77-90. Bastante instructivo, el informe producido por la USP, "Continuidade autoritária e construção da democracia", coordinado por Sérgio Adorno.

43 BERCOVICI, Gilberto. O direito constitucional passa, o direito administrativo permanece: a persistência da estrutura administrativa de 1967. In: TELES, Édson; SAFATLE, Vladimir (Org.). O que resta da ditadura: a exceção brasileira. São Paulo: Boitempo, 2010. p. 84.

44 Ambos expone las dos consecuencias posibles de la concesión de la amnistía: (1) absolutas, la "amnistía amnésica", que esconde completamente delitos del pasado prohibiendo las investigaciones, ejemplificando con el Decreto chileno 2.191/78 - beneficiando al General Augusto Pinochet por los delitos practicados en el coup d'état de 11.09.1973 y 10.03.1978 - y con el reciente Acuerdo de Paz de Sierra Leona (07.07.1999); (2) condicionadas, que no causa impunidad, sino que condiciona la extensión del beneficio a la realización de ciertos actos o ciertas concesiones por parte del beneficiário, como v.g. la deposición de las armas, así 
menor para la transición pacífica" ${ }^{45}$ estimulando la creación de un amplio acuerdo entre las fuerzas sociales que, todavía, no legitima per se la opción por la represividad penal. ${ }^{46}$ Hubo en Brasil quien pensó que la amnistía general aprovechaba a ambas posicionas en conflicto. $^{47}$

\section{(1) El Informe Araguaia}

La Corte Interamericana de Derechos Humanos condenó a Brasil por la desaparición de 62 personas-miembros de la Guerrilla del Araguaia, inaugurando un precedente valioso para la actuación persecutoria de la Fiscalía Federal. "Según el Juez ad hoc Roberto Caldas, la sentencia no se aplica solamente a las guerrillas. 'La decisión se aplica a todos los casos de tortura, desaparición forzada y ejecución sumaria ocurridas en dictadura" Brasil, un signatario de la Convención Americana sobre Derechos Humanos, tiene el deber de cumplir las decisiones de la Corte. El Supremo Tribunal Federal fue instado a manifestarse sobre: “(a) la no-revelación del destino de los restos mortales de los desaparecidos, (b) la falta de divulgación de las circunstancias de las desapariciones, (c) la impunidad de los autores de esos delitos" " 48 Todavía, todo nos lleva a creer que el STF no va a reconocer la eficacia integradora de la decisión de la Corte Interamericana. El Presidente del STF, Min. Cezar Peluso, "afirmó que la decisión de la Corte Internacional "no revoca, no anula, no casa' la del Supremo" válida apenas en el "campo de la convencionalidad". El Min. Marco Aurélio Mello comunicó su asentimiento: “Es una decisión tomada en el ámbito internacional y no en el interno. Lo que nosotros decidimos en el STF fue a partir del derecho nacional. En la práctica, el efecto no será ninguno" 49

como pasó con la Ley de Promoción de la Unidad Nacional y la Reconciliación n. 34 de 1995, en Sudafrica. AMBOS, Kai. O marco jurídico da justiça de transição. Trad. Pablo Rodrigo Aflen da Silva. In: AMBOS, Kai; ZILLI, Marcos et al. (Org.). Anistia, justiça e impunidade: reflexões sobre a justiça de transição no Brasil. Belo Horizonte: Ed. Fórum, 2010. p. 66-67; 75-76.

45 Crítico, SANTOS, Roberto Lima. Crimes da ditadura militar: responsabilidade internacional do Estado brasileiro por violação aos direitos humanos. Porto Alegre: Núria Frabis Editora, 2010. p. 83 y ss.

46 Así entendió FRONZA, Emanuela. Profili penalistici del negazionismo. Rivista Italiana di Diritto e Procedura Penale, Milano, v. 42, n. 3, 1999. p. 1.070 en el campo del negacionismo.

47 Como parece ser el caso del pitoresco (GABEIRA, Fernando. O que é isso companheiro? São Paulo: CODECRI, 1979.), en el que narra el secuestro del embajador estadounidense Charles Elbrick, como instrumento de presión de la dictadura militar para la liberación de otros 15 miembros de los grupos de la resistencia armada.

48 WEICHERT, Marlon Alberto. Responsabilidade internacional do Estado brasileiro na promoção da justiça transicional. In: SOARES, Inês Virgínia Prado (Org.). Memória e verdade: a justiça de transição no Estado democrático brasileiro. Belo Horizonte: Ed. Fórum, 2009. p. 159. Aunque se pueda alegar que los actos de violación a los derechos humanos se consumaron antes de la ratificación de la Convención, entiende Weichert (con referencia al precedente Almonacid Arellanos versus Chile, 26.09.2006) que "la persistencia de la omisión en revelarles, apurarles y punirles" recomienda la reprovación al País.

49 "JUIZ internacional vê caminho para novas ações contra Anistia. Folha de S.Paulo, São Paulo, 16 dez. 2010. p. A-15.; crítico, "tratase, todavía, de una condenación moral al Brasil, sin efectos prácticos. En la práctica, 
(2) La Ley de Amnístia brasileña (Ley n. 6.683/79)

Todavía, la amnistía no fue igualitaria, pues no atcanzó a los condenados por delitos más graves (terrorismo, asalto y secuestro). ${ }^{50}$ Piovesan confronta la composición de los delitos como "conexos": "No se puede hablar de la conexidad entre hechos practicados por el delincuente y por las acciones de su víctima. La amnistía perdonó a esos y no a aquellos; perdonó a las víctimas y no los que delinquen en nombre del Estado. Además de eso, es inadmisible que el crimen de tortura sea concebido como crimen político, pasible de amnistía y prescripción (...) La tortura es crimen de lesa humanidad, considerado imprescriptible por el orden internacional. Demanda del Estado el deber de investigar, procesar, punir y reparar la violación realizada, asegurando a la víctima el derecho a la justicia y el derecho a la prestación jurisdiccional efectiva" ${ }^{51}$

\section{(3) La ADPF-153}

En 2008 el OAB (Ordem dos Advogados do Brasil - Consejo de Abogados) propuso la acción de no-cumplimiento del precepto fundamental (ADPF-153), cuestionando la constitucionalidad de los efectos de la amnistía, basada en los argumentos siguientes: (1) ausencia de conexión entre los crímenes comunes y crímenes políticos; (2) y por equiparar delitos de distinta naturaleza, ofensa a la legalidad; (3) por la supresión de los efectos a los actos calificados como terrorismo, asalto, secuestro y atentado contra la persona, alegó violación de la igualdad de tratamiento; (4) no-respeto al derecho a la verdad; (5) desprestigio al principio republicano, por reconocer una ley de amnistía producida en contexto político totalitario. ${ }^{52}$ Todavía, el STF juzgó improcedente la acción. El comportamiento decisorio del Min. Eros Grau rechazó la interpretación del Consejo de los Abogados, reafirmando el sentido normativo de las mediaciones de "amplio acuerdo social" de la Ley de Amnistía, amplio, general y irrestricto, como fue consagrado por la historiografía tradicional. La Corte Interamericana, de la misma forma que lo hizo, p. ej., en el caso Barrios Altos versus Peru, reprueba la auto-amnistía ${ }^{53}$ como perpetuación del

el STF chanceló la impunidad de los torturadores mientras decidió, en abril, que la Ley de Amnistía no sería alterada", SILVA, Fernando de Barros e. Ecos da ditadura. Folha de S.Paulo, São Paulo, 27 dez. 2010. p. A-2. Asi en MEZAROBBA, Glenda. Um acerto de contas com o futuro: a anistia e suas conseqüências, um estudo do caso brasileiro. São Paulo: Humanitas, 2006. p. 52 y ss.

51 PIOVESAN, Flávia. Direito internacional dos direitos humanos e lei de anistia: o caso brasileiro. In: SOARES, Inês Virgínia Prado (Org.). Memória e verdade: a justiça de transição no Estado democrático brasileiro. Belo Horizonte: Ed. Fórum, 2009. p. 204-205.

s2 En detalles, AMBOS, Kai; ZILLI, Marcos et al. (Org.). Anistia, justiça e impunidade: reflexões sobre a justiça de transição no Brasil. Belo Horizonte: Ed. Fórum, 2010. p. 174-175.

53 Por la invalidez de la "auto-amnistía", SANTOS, Roberto Lima. Crimes da ditadura militar: responsabilidade internacional do Estado brasileiro por violação aos direitos humanos. Porto Alegre: Núria Frabis Editora, 2010. p. 151 y ss. 
sensación general de impunidad. El Min. Eros Grau, sin embargo, rechazó la aplicación de la Convención de las Naciones Unidas contra la Tortura, motivando su decisión con base en la prohibición de la retróactividad. ${ }^{54}$

También el tema de la imprescritibilidad fue superado por el STF. El tema de la prescripción ${ }^{55}$ escinde el procedimiento entre la materialización de valores de justicia y el manejo operacional de la juridificación del derecho. A contrario sensu de la Resolución n. 2.338/1967 de la Asamblea General de las Naciones Unidas, no se consideró que la negociación haya sido desequilibrada, "impuesta por uno de los lados" 56 En opinión bastante resolutiva sobre la experiencia brasileña, uno de los juristas más importantes de Brasil, Tercio Sampaio Ferraz Jr.: “(la amnistía) no apaga propiamente la infracción, pero el derecho de punir. (...) Amnistiar a los torturadores que accionaron dentro de un cuadro político a él obviamente conexo no significa violar la Constitución ni los tratados internacionales que proscriben la tortura como un crimen contra la humanidad. (...) Una reinterpretación de la ley, sobretodo con la finalidad de punir militares por actos de tortura, reverterá el argumento jurisprudencial, pues irá solapar la extensión de la amnistía a los terroristas, haciendo con que todo el universo de evaluaciones mutuamente negativas (exclusión/inclusión de terrorista/torturador) tenga que ser de vuelta discutido. (...) Habrá de no se olvidar que tratados internacionales consideran, p. ej., también el secuestro motivado por razones políticas un crimen contra la humanidad, igualmente imprescritible. Con eso, volvería la necesidad de evaluaciones de prácticas criminosas y sus consecuencias de ambos los lados, en prejuicio del correcto entendimiento de una amnistía general e irrestricta" 57

54 Regístrese la posición opuesta de Kai Ambos, en el sentido de "relativización" de la prohibición de la retroactividad y del principio de la determinación (taxatividad), citado según BATISTA, Nilo. Nota introdutória. In: DIMOULIS, Dimitri (Org.) Justiça de transição no Brasil. São Paulo: Saraiva, 2010. p. 14.

s5 Justificando la imprescritibilidad bajo una "construcción inherente del ordenamiento", MELLO, Celso Antonio Bandeira de. Imprescritibilidade dos crimes de tortura. In: SOARES, Inês Virgínia Prado (Org.). Memória e verdade: a justiça de transição no Estado democrático brasileiro. Belo Horizonte: Ed. Fórum, 2009. p. 137.

56 AMBOS, Kai; ZILLI, Marcos et al. (Org.). Anistia, justiça e impunidade: reflexões sobre a justiça de transição no Brasil. Belo Horizonte: Ed. Fórum, 2010. p. 188.

57 FERRAZ JUNIOR, Tercio Sampaio. Anistia: geral e irrestrita. Folha de S.Paulo, São Paulo, 16 ago. 2008. Opinião; en contra de T. Ferraz $J r$., habla de uma "amnesia sistematica en relacion a los crimenes de um Estado ilegal", y "(...) se trata principalmente de intentar transmitir la idea de que toda violencia es equivalente, que no hay diferencia entre violencia y contraviolencia", SAFATLE, Vladimir. Do uso da violência contra o Estado ilegal... Op. cit., p. 241 y 242. Remontando a la cuestión de los "dos demónios", crítico, SANTOS, Roberto Lima. Crimes da ditadura militar: responsabilidade internacional do Estado brasileiro por violação aos direitos humanos. Porto Alegre: Núria Frabis Editora, 2010.p. 144 y ss. 
(4) La búsqueda de control internacional en Brasil

Sectores organizados de la sociedad se empeñaron en la búsqueda de control internacional de los juzgados. El intento atiende a una idea de construcción principiológica de las convenciones internacionales en torno del "principio de la justicia universal" (Weltrechtsprinzip). En nuestro particular, interesa que con él los Estados adquieren la obligación de "exigir la incorporación de los medios indispensables al ejercicio de la jurisdicción universal a los sistemas jurídicos internos (de nuevo, la Convención contra la Tortura de 1984, art. 5.2), o, de modo más ambicioso, obligar a las autoridades nacionales a realizar efectivamente las persecuciones (p. ej., la Convención de Ginebra I de 1949, art. 49)" 58 En eses términos y condiciones se crea una sistemática de control internacional que organiza la normativa internacional de combate a la tortura: "Declaración Universal de los Derechos del Hombre de 1848 (art. $5^{\circ}$ ), Pacto Internacional sobre Derechos Civiles y Políticos de 1966 (art. 7º), Convención Americana sobre Derechos Humanos de 1969 (art. 5.2) y Convención contra Tortura y otros Tratamientos o Penas Crueles, Deshumanos o Degradantes de 1984" 59 El control internacional puede incluso llegar hasta una delicada acusación de mala-fé de los Tribunales locales, como si estuviesen prevaricando para preservar los intereses y dejar impunes a los autores. ${ }^{60}$

Sin embargo, la construcción sistemática se fragiliza por conceder a los Estados la posibilidad de manejo técnico del ejercicio de la jurisdicción, incluso por permitirles "espontáneamente" la elección de la "competencia universal de sus tribunales para el juzgamiento de los crímenes", ${ }^{61}$ relativizando en demasía la integración del comportamiento decisorio en los ámbitos nacional y supra-nacional. La crítica brasileña accede también a las insuficiencias de las determinaciones de la costumbre internacional, cuyas resoluciones de soft law "no resuelven el problema, sino que los esconde" 62

Coherente hasta las últimas consecuencias, si así lo quisiera, sería entonces si las incriminaciones alcanzasen a los verdugos estadounidenses que coordinaron el

58 MACHADO, Maíra Rocha. A internacionalização do direito penal: a gestão de problemas internacionais por meio do crime e da pena. São Paulo: Ed. 34 LTda., 2004. p. 85-86.

59 AMBOS, Kai; ZILLI, Marcos et al. (Org.). Anistia, justiça e impunidade: reflexões sobre a justiça de transição no Brasil. Belo Horizonte: Ed. Fórum, 2010. p. 187.

60 Así resalvó AMBOS, Kai. O marco jurídico da justiça de transição. Trad. Pablo Rodrigo Aflen da Silva. In: AMBOS, Kai; ZILLI, Marcos et al. (Org.). Anistia, justiça e impunidade: reflexões sobre a justiça de transição no Brasil. Belo Horizonte: Ed. Fórum, 2010. p. 105, exigiéndose, todavia, la configuración de la "intención de impunidad" de los órganos responsables por el juicio.

61 MACHADO, Maíra Rocha. A internacionalização do direito penal: a gestão de problemas internacionais por meio do crime e da pena. São Paulo: Ed. 34 LTda., 2004. p. 86-87.

62 SWENSSON JÚNIOR, Lauro Joppert. Punição para os crimes da ditadura militar: contornos do debate. In: DIMOULIS, Dimitri (Org.). Justiça de transição no Brasil. São Paulo: Saraiva, 2010. p. 53. 
asalto a la libre organización de la vida social en Latinoamérica, acusación con el mismo impetu del arriba mencionado John Dinges.

La discusión del ordenamiento jurídico de entonces estira sus brazos hasta la Ley de Reconocimiento de los Muertos y Desaparecidos (Ley n. 9140/95 - "Lei de Reconhecimento dos Mortos e dos Desaparecidos"); seguida por la tipificación del delito de tortura (Ley 9455/97); y también la Ley de Reparación (Ley 10559/2002), que garantizó reparación económica a los amnistiados. ${ }^{63}$ Las cito solamente para señalar que la experiencia brasileña cuenta además con expresivo activismo de la Fiscalía Federal. ${ }^{64}$ por ejemplo, en la "Carta de São Paulo", producida para coordinar las actuaciones en Brasil, Peru, Chile y Argentina.

Por ahora, lo que nos importa a nosotros es el derecho a la información. ${ }^{65}$ Remontando a Ricoeur, E. Teles habla de la adopción del silencio como acción política del tipo "silencio del no decir" e imposición de un discurso hegemónico. ${ }^{66}$ Aunque el Gobierno Lula da Silva haya producido el más amplio proyecto de Ley de nuestra historia (el Proyecto de la Ley General de Acceso a la Información), la superación del sigilo de informaciones permanece todavía bajo dudosa manipulación. Pero para Lula da Silva, "desde lo alto y con una aceptación (popular) de más del 80\%", no le pareció conveniente "arbitrar contra algunos de sus colaboradores directos" 67 o mismo dejar que sus antecesores se enfrenten con los eventuales conflictos internacionales que podrían surgir. Sea como fuere, está en vigor en Brasil el "sigilo eterno" menospreciando el derecho fundamental a la verdad, sin hablar de los compromisos internacionales sugeridos por el art. $5^{\circ}, \S 2^{\circ}, \mathrm{CF} / 88$. No sólo al inviabilizar que los indivíduos puedan acceder a las informaciones se está desconsiderando la recomendación de transparencia de los actos públicos - así en el principiológico art. 37, CF/88 y también en el art. $5^{\circ}$ XIV, XXXIII, $\mathrm{CF} / 88{ }^{68}$ De mencionarse además los intentos de elaboración de una "Política Nacional de

63 Mayores informaciones sobre esos instrumentos legales, TAVARES, André Ramos; AGRA, Walber de Moura. In: SOARES, Inês Virgínia Prado (Org.). Memória e verdade: a justiça de transição no Estado democrático brasileiro. Belo Horizonte, 2009. p. 82-88.

64 Véase la descripción de acciones de la Fiscalia brasileña en: FÁVERO, Eugênia Augusta Gonzaga. Crimes da ditadura: iniciativas do Ministério Público Federal em São Paulo. In: SOARES, Inês Virgínia Prado (Org.). Memória e verdade: a justiça de transição no Estado democrático brasileiro. Belo Horizonte: Ed. Fórum, 2009. p. 228-231.

65 MP 228, Lei 11.111/1995. COSTA, Célia Maria Leite. O direito à informação nos arquivos brasileiros. In: FICO, Carlos et al. (Org.). Ditadura e democracia na América Latina: balanço histórico e perspectivas. Rio de Janeiro: FGV Editora, 2008. p. 17 y ss.

66 TELES, Edson Luís de Almeida. Brasil e África do Sul... Op. cit., p. 127.

67 "INFORMAÇÃO pública não é prioritária ao Planalto: divergências no governo explicam o desinteresse de Lula sobre o tema. Folha de S.Paulo, São Paulo, 05 dez. 2010. p. A-13.

68 "El derecho a la información, o libertad informacional (Informationelle Selbstbestimmung), tiene como premisa el hecho de que el poder público no detiene información en su propio interés, sino que lo hace en beneficio de todos los miembros de la colectividad. En un Estado republicano y democrático, el acceso a información manipulada por el Poder Público es, por lo tanto, regla. Cualquier intento de limitar su acceso 
Arquivos Públicos - Ley n. 8159/1991" (y otras reglamentaciones de la Ley 9784/99) y el derecho de certificación, en el inciso XXXIV, “enlodando la sumisión de la Administración Pública en el principio de la publicidad", ${ }^{69}$ todas medidas que tramitan a paso lento, demasiado lento por la importancia que representan, las cuales, a diferencia de las otras medidas administrativas, ellas sí tienen la potestad de brindar elementos necesarios para la reconstrucción de la memoria histórica, dependiente de las fuentes históricas. Y esa capacidad de conducir las posibilidades de realización individual (en el caso, que a uno le sea jurídicamente permitido acceder a los datos que le permitan la reconstrucción de su propia historia) es justo lo que se espera de las normas jurídicas. Mismo porque, sería solamente así, recomponiendo las piezas del rompecabezas, que uno podría recuperar el sentido de la memoria histórica.

Honorables excepciones, aquellos que accedieron a las fuentes históricas por una cierta intimidad con los verdugos de la dictadura, fueron responsables por producir documentos literarios excepcionales, como es el caso de la Autópsia do medo ("Autopsia del miedo: vida y muerte del comisario Sérgio Paranhos Fleury"), de Perceval de Sousa, ${ }^{70}$ y la ruidosa colección de Élio Gaspari. ${ }^{71} \mathrm{~A}$ la excepción de Direito à memória e à verdade ("Derecho a la memoria y a la verdad"), documento oficial del Estado brasileño, en que se relataron las atrocidades del régimen dictatorial y se atribuyó la autoría a los integrantes de las Fuerzas Armadas, el silencio de los archivos calificados como peligrosos para la seguridad nacional nos hace recordar la posición de Barack Obama, que dio un paso atrás en la abertura de los archivos de Guantánamo.

4. El enclave de los juicios de transición: límites racionales de la juridificación del conflicto

Ahora lo que propongo es un ejercicio del aspecto saludable de la polémica. Creo que hoy podríamos, sin el estigma de descalificación de las opiniones contrarias, alzar la cuestión al nivel de problema científico. Espero que la hostilización del objeto no impida

solamente se justifica cuando hubiera notorio y esencial interés público, no bastando hacerse del discurso centrado en la primacía absoluta de la autonomía pública para impedir el acceso a la información”. KISHI, Sandra Akemi Shimada. Direito à informação e à participação na Justiça de Transição. In: SOARES, Inês Virgínia Prado (Org.). Memória e verdade: a justiça de transição no Estado democrático brasileiro. Belo Horizonte: Ed. Fórum, 2009. p. 263.

69 OLIVEIRA, João Roberto Pimenta. Princípio da publicidade, arquivos públicos e justiça de transição. In: SOARES, Inês Virgínia Prado (Org.). Memória e verdade: a justiça de transição no Estado democrático brasileiro. Belo Horizonte: Ed. Fórum, 2009. p. 301.

70 SOUZA, Percival. Autopsia do medo: vida e morte do delegado Sérgio Paranhos Fleury. São Paulo: Globo, 2000.

71 GASPARI, Elio. A ditadura envergonhada. São Paulo: Cia. das Letras, 2002; GASPARI, Elio. A ditadura escancarada. São Paulo, 2002; GASPARI, Elio. A ditadura derrotada. São Paulo: Cia. das Letras, 2003; GASPARI, Elio. A ditadura encurralada. São Paulo: Cia. das Letras, 2004. 
observar la posición del problema en todas sus dimensiones, interponiendo concepciones subjetivas a un proceso de investigación - antes de todo - histórico. Y más allá de eso, que la colocación de las dificultades teóricas puedan intervenir con algún significado en la resolución del problema, la creación de instrumentos jurídicos de preservación de la memoria histórica. Si traer las particularidades del caso brasileiro tiene alguna validez, creo que está en viabilizar la construcción de unidad - de las diferencias - analizadas las formas de evolución de sentido operacional de las instituciones y de la represividad.

El enclave de los juicios de transición es un problema jurídico-político. Günther Teubner desarrolla esa cuestión bajo su concepción del trilema regulatorio de las irritaciones entre el derecho, la política y la sociedad. Esencial para la comprensión del problema es que, según Teubner, "la juridificación no resuelve los conflictos, sino que simplemente los aliena: o sea, mutila los conflictos sociales, reduciéndolos a un mero caso judicial, y de ese modo excluye cualquier posibilidad de una resolución socialmente adecuada y prospectivamente orientada" 72 El tema es que la racionalidad procedimental no es idónea a construir la verdad histórica - así como también entendió Fronza, "la verdad es la verdad y no necesita ser la verdad legal. Mismo a partir del momento en que esa verdad legal se torna sospecha de poder ser instrumentalizada", y si el procedimiento no logra incluso a reconstituir los hechos, "se arriesga a caminar en la dirección del mal que se propone a combatir" ${ }^{73}$ sometiendo la aplicación del derecho no a criterios jurídicos de racionalidad, sino dejándole a sabor de la soberanía decisoria de la política, en casos de superposición de la política al derecho ${ }^{74}$ típicas al que $M$. Neves llamó de "corrupción sistémica" ${ }^{75}$ Dimoulis, luego de afirmar inadecuación del espacio procesal para enfrentar los problemas políticos, aconseja una tomada de posición de las fuerzas sociales progresistas derecho en el campo de la política: (1). combate a las prácticas autoritarias en los distintos sectores de la vida social en Brasil; (2) entender la "reparación" como

72 TEUBNER, Günther. Verrechtlichung: Begriff, Merkmale, Grenzen, Auswege. In: KÜBLER, Friedrich (Org.). Verrechtlichung von Wirtschaft, Arbeit und soziale Solidarität. Baden-Baden: Nomos, 1984. p. 289-344. p. 289-344. Esa crítica a la juridificación en el ámbito penal se encuentra originalmente en la investigación de FERNANDES, Fernando. O processo penal como instrumento de política criminal. Coimbra: Almedina, 2001. p. 94 y ss.

73 La argumentación de Fronza fue desarrollada en el contexto de los delitos de negacionismo, FRONZA, Emanuela. Profili penalistici del negazionismo. Rivista Italiana di Diritto e Procedura Penale, Milano, v. 42, n. 3, 1999. p. 1074 y nota 199.

74 La comprensión de la política en los juicios del pasado asumen una dimensión especialmente privilegiada en SCHMITT, Carl. Das internationalrechtliche Verbrechen des Angriffskrieges und der Grundsatz 'Nullum crimen, nulla poena sine lege' Berlin: Duncker \& Humblot, 1994; y también en KIRCHHEIMER, Otto. Political Justice: the use of legal procedure for political ends. Princeton: Greenwood Press, 1961; reciente, admitiendo el juicio sobre el pasado como superposición de la politica sobre el derecho, KASTNER, Fatima. Das Welttheater des Pardons: zum Verhältnis von Recht, Vergebung und Gedächtnis. In: TEUBNER, Günther (Org.). Nach Jacques Derrida und Niklas Luhmann: zur (Un-)Möglichkeit einer Gesellschaftstheorie der Gerechtigkeit. Stuttgart: Lucius \& Lucius, 2008. p. 153-166.

75 NEVES, Marcelo. A constitucionalização simbólica. 2. ed. São Paulo: WMG Martins Fontes, 2006. p. 146 y ss. 
garantía de iniciativas político-sociales; (3) reforma radical del aparato policial brasileño; (4) experimentación de formas democráticas alternativas. ${ }^{76}$

Me parece que hay una cierta contradicción en concedernos juicios de valor ético-sociales a individuos que supuestamente estarían más allá de eso en su constitución moral (en cuanto personas). Con las posibilidades de manipulación procedimental (y del sentido que de esa forma se adscribe a la norma jurídica), la propia presencia de la historia se arriesga al obscurecimiento, por supuesto que bajo ciertos intereses. Un coterráneo de Uds., Pastor, lo asume abiertamente: "en una sociedad no paternalista creemos que solamente la consciencia individual esté apta a formular juicios sobre el pasado. El recordar o el olvidar (...) no tiene lugar en una sociedad abierta para las versiones oficiales de la historia" 77 Estudiar los procedimientos no puede servir para legitimarlos o justificarlos aceptando sus presupuestos de desintegración de la realidad en nuestro caso, de la verdad histórica. Por su parte, la conducción de la operacionalidad del derecho penal puede llevarnos a alcanzar unos cuantos logros tácticos, logros políticos que quizás vehiculizarían el reproche a ciertas preferencias autoritarias. Porque si fuese de esa forma, la consecuencia es un incontrolable subjetivismo ${ }^{78}$ del comportamiento decisorio $^{79}$ en el derecho. Concederles a las víctimas una sensación de venganza - y no propiamente de justicia de naturaleza penal -, de suerte que lo que sufrieron ellas sea convertido en revanchismo penal y peligrosa actitud de selectividad. Y que puedan servir de pretexto para la construcción de precedentes jurisprudenciales de futura actuación reversa. Si es cierto que hoy se desfruta de una posición orgánica en los tribunales, mañana podrá no pasar lo mismo. Lo que quiero problematizar es que ese revanchismo el derecho penal como vendetta - podría infectar al derecho con la perversa paradoja de la selectividad; a quién le atribuye la responsabilidad penal, bien al revés de cuales son los hechos - objetivamente - punibles y que puedan atender a las finalidades de la pena de planteamiento preventivo más allá de un simples retribucionismo. Nilo Batista, penalista brasileño internacionalmente reconocido por sus posiciones por así decir "progresistas", dijo en primer término: "los internacionalistas se apropiaron de la pena por los caminos

76 DIMOULIS, Dimitri. Justiça de transição e função anistiante no Brasil: hipostasiações indevidas e caminhos de responsabilização. In: DIMOULIS, Dimitri (Org.). Justiça de transição no Brasil. São Paulo: Saraiva, 2010. p. 122.

77 PASTOR, Daniel. Processi penali solo per conoscere la verità? L'esperienza argentina. In: FRONZA, Emanuela; FORNASARI, Gabriele (Org.). Il superamento del passato e il superamento del presente: la punizione delle violazioni sistematiche dei diritti umani nell'esperienza argentina e colombiana. Trento: Universitá degli Studi di Trento, 2009. p. 160.

78 REALE JUNIOR, Miguel. Razão e subjetividade no direito penal. Ciências Penais, v. 00, p. 226-249, 2004.

79 Bajo la orientación de la observación sociológica luhmanniana, pude en otra oportunidad apreciar las diferenciaciones funcionales de los comportamientos sociológicos en ámbito económico, político y jurídico, DINIZ, Eduardo Saad. A sociologia da decisão: a econômica, a política, a jurídica. Revista da Faculdade de Direito da Universidade de São Paulo, São Paulo, v. 102, p. 953-965, jan./dez.2007. p. 953 y ss. 
teóricos legitimantes (retribucionismo o prevencionismo) y luego, ellos no tienen que interesarse por la realidad de las criminalizaciones y ejecuciones penales y sus resultados sociales, los que frecuentemente tienden a recurrir a ella como superación simbólica de la crisis de eficacia de los derechos humanos (... ${ }^{\prime 80}$ Sin la idea preventiva que orienta la construcción de la racionalidad jurídica, la integración social mediante el derecho $0^{81}$ - solución de problemas sociales por medios jurídicos - se reduciría a la absorción de los deseos sociales, sin que, paradojalmente, los pueda revolver en su realidad concreta. No por casualidad, Teubner recurre al clásico fiat justitia, pereat mundus, "haga justicia, y perecerá el mundo" La problematización científica en el ámbito procedimental del derecho podría embotar la racionalidad que nos conduciría a una real fundamentación de la superación del pasado, al restablecimiento de la memoria histórica y de todas las posibilidades prácticas de subjetivación - formación individual - que se permiten a partir de ella.

Parece que el grande enclave del ajuste de cuentas del derecho versus el autoritarismo consiste en el empleo de juicios abstractos derivados de los constructos procesales y de todas las dificultades de la teoría de la prueba que le son inherentes ${ }^{82}-$ de vuelta, la mutilación del conflicto - para aprehensión de un movimiento científico de la realización de la historia (producción y reproducción de las formas sociales). Sería así si el intento fuese justo la superación del enorme "simbolismo" en que está envuelta la discusión del combate a la opresión y a la violencia ilimitada. La cuestión que queda sin contestar es la siguiente: ¿estaríamos aptos para juzgar a los ciudadanos con instrumentos idóneos, y con esos mismos instrumentos construir un orden justo, coherente y solidario?

5. La superación del presente en Brasil: a título de colofón

La experiencia autoritaria à la brasileira produjo un espacio de disputa entre la combatividad (resistencia) y la militarización de las artes,$^{83}$ incluso el samba carioca, fenómeno mundial, fue instrumentalizado al servicio de la dictadura. ${ }^{84}$ Uno de los grandes íconos del "samba de resistencia", Chico Buarque, incitaba a la militancia a construcción

80 BATISTA, Nilo. Nota introdutória. In: DíMOULIS, Dimitri (Org.). Justiça de transição no Brasil. São Paulo: Saraiva, 2010. p. 14. p. 13-14.

81 Crítico, MARTINS, Antonio. Sobre direito, punição e verdade: reflexões acerca dos limites da argumentação jurídica. In: DIMOULIS, Dimitri (Org.). Justiça de transição no Brasil. São Paulo: Saraiva, 2010. p. 82.

82 MARTINS, Antonio. Sobre direito, punição e verdade: reflexões acerca dos limites da argumentação jurídica. In: DIMOULIS, Dimitri (Org.). Justiça de transição no Brasil. São Paulo: Saraiva, 2010. p. 84.

83 STEPHANOU, Alexandre Ayub. Censura no regime militar e militarização das artes. Porto Alegre: Edipucrs, 2001. p. 113 y ss.

84 TAVARES, Luiz Edmundo; FREIXO, Adriano de. O samba em tempo de ditadura: as transformações no universo das grandes escolas do Rio de Janeiro nas décadas de 1960 e 1970. In: FREIXO, Adriano de; MUNTEAL FILHO, Oswaldo (Org.). A ditadura em debate: Estado e sociedade nos anos do autoritarismo. Rio de Janeiro: Contraponto, 2005. p. 53. 
de una vida futura libre de las perversiones totalitarias, "Apesar de você, amanhã há de ser outro dia" Lamentablemente la resolución estética de Chico Buarque, y el arreglo según la vida futura, solamente me permite identificar que "mañana" fue tal cual ayer, que el problema del autoritarismo en Brasil es el problema de la superación del presente institucional. Brasil permanece sin grandes salidas estéticas para el problema, como por ejemplo lo que hizo entre Uds. el Nadie nada nunca, de Juan José Saer; nos faltaría, conforme la inteligente crítica de Lísias, caminar "mas allá de apuntar al apagamiento histórico y al pacto con la elite (...) y proponer una alternativa (...) en ámbito ficcional" 85 Ya en el ámbito judicial, los procesos de concientización racional del derecho sufren de una cierta "infra-complejidad" bajo el condicionamiento de la política. Si el intento de racionalizar la comprensión del procedimiento nos remite a las teorías dominantes de la "interpretación político-criminal" me faltaría precisar lo qué es política criminal. ¿Si ella adviene de determinaciones del ámbito político mismo, del proceso legislativo ampliamente considerado, o de una política social, o todavía si sería la orientación de la política-jurídica que conduce a la interpretación de los hechos por los jueces - al final, de qué estamos hablando? En Brasil, por ejemplo, más allá de todas las representaciones que oponen Fernando Henrique Cardoso (el intelectual de la Universidad de São Paulo) - 1994-2001 y Lula da Silva - 2002-2010 (el líder operario que emergió del piso de las metalúrgicas), cuyos rasgos de desarrollo económico no sorprende el continuismo histórico. Ambos estuvieron alineados en la agenda corporativa neoliberal, ${ }_{,}^{86}$ a pesar del popular programa asistencialista "Bolsa Família" que otorgó fama a Lula en el escenario internacional. "FHC(ardoso) y Lula contribuyeron para profundizar la "militarización" en lugar de la 'civilianización' de la seguridad pública (...)" ${ }^{87} \mathrm{Y}$ a pesar de una analítica más detenida, lo que quiero problematizar es que el déficit de maduración histórica de

85 LÍSLAS, Ricardo. Dez fragmentos sobre a literatura contemporânea no Brasil e na Argentina ou de como os patetas sempre adoram o discurso do poder. In: TELES, Édson; SAFATLE, Vladimir (Org.). O que resta da ditadura: a exceção brasileira. São Paulo: Boitempo, 2010.p. 326 y 327.

86 Con apoyo en las autorizadas críticas de Leda Paulani, evidénciese que el gobierno de Lula fue neoliberal porque: (1) adhesión a la plataforma de valorización financiera internacional; (2) la adopción de una política macroeconómica de primacía de la dinámica de los negocios corporativos; (3) política social basada en "políticas compensatorias de renda", vehiculando falsa percepción de la inclusión social. En detalles, PAULANI, Leda. Brasil Delivery: servidão financeira e estado de emergência econômico. São Paulo: Boitempo, 2008. p. 70-71. Apoyándose en el entendimiento de Perry Anderson sobre la teoría neoliberal, Carvalho también esquematiza el neoliberalismo del gobierno Lula: (1) prioridad absoluta para los derechos del capital; (2) ocultamiento de las relaciones capital-trabajo y responsabilización del individuo frente al capital; (3) despolitización de la política económica, tratada como técnica universal; (4) abertura de nuevos espacios para la valorización del capital; (5) responsabilización de los países independientes por los efectos del desorden financiero internacional. En detalles, CARVALHO, Carlos Eduardo. Governo Lula, o triunfo espetacular do neoliberalismo. Margem Esquerda: Ensaios Marxistas, São Paulo, n. 3, 2004. p. 135-136.

87 ZAVERUCHA, Jorge. Relações Civil-Militares: o legado autoritário da constituição brasileira de 1988. In: TELES, Édson; SAFATLE, Vladimir (Org.) O que resta da ditadura: a exceção brasileira. São Paulo: Boitempo, 2010. p. 69. 
nuestra sociedad promovió al nivel parlamentario el payaso Tiririca con aproximados 1,3 Millones votos, o, si bien el nacionalismo exacerbado de la pasión futbolística nos une a todos, Romário, el protagonista del Mundial de 94, recién fue conducido a la condición de legislador. Lo peor no es que son impresentables para la vida pública, sino que traen con ellos dinosaurios del período dictatorial bajo un colorido procedimiento de legitimidad democrática: las elecciones populares regidas por el sistema electoral de representación proporcional (art. 105 y ss., Ley n. 4737/1965, hasta hoy en vigor). Si bien Uds. pueden ponderar sobre los recientes índices econométricos que ostenta Brasil frente al mundo, debo preguntarles: son esas personas - o mejor dicho: es la desacreditada identidad institucional brasileña quien va "legislar" sobre la verdad histórica? Lo mismo, salvando algunas excepciones, parece valer para la inestabilidad decisoria de las cortes nacionales y de control jurídico supranacional. La falsa percepción de la democracia es una amenaza a la propia democracia. ${ }^{88}$ Así también parece ser el caso del juicio de transición limitado al subjetivismo decisorio.

Finalmente, para la construcción racional del derecho (penal), la ausencia de referenciales éticos no fundamenta la libre autodeterminación de los individuos. Un poco escéptico en cuánto al lugar del derecho en la sociedad, les pregunto si no estaría el derecho quizás cumpliendo su función histórica de conservadurismo, o si la Historia pretende del derecho algo que no está al alcance de su propia racionalidad, cuándo la idea de compromiso histórico provoca una pérdida de un referencial teórico. Ese enclave es una piedra en el zapato del deseo más íntimo que tenemos de desterrar la verdad y desvendar la ciega Justicia. Pero como hacer de ese sentimiento de objeción al autoritarismo - y de sufrimiento humano - una construcción jurídica racional para orientar la operacionalidad de la "Justicia de Transición", precisamente ahí está el lamento de la racionalidad jurídica. Y expongo mis propias dudas, porque no sé si con eso llegaríamos a construir prácticas de subjetivación y consolidación de la consciencia de la libertad más allá del anacronismo histórico que podría representar las disputas políticas en el ámbito del derecho, si con eso los pueblos que fueran violentamente puestos en las rodillas por modelos de Estado autoritarios podrán levantarse; y alcanzar un nivel de vida efectiva de la experiencia de la realización de la verdad, objetivamente, así como objetivas son las carnaduras concretas de la individuación humana; y si así, un poco más allá de los procesos de subjetivación de la memoria histórica en el derecho, porque dudo que él pueda superar sus propios enclaves de racionalidad jurídica - de la juridificación de la historia - para crear una realidad en la cual el hombre no sea reducido a abstracciones sociales.

88 ZAVERUCHA, Jorge. Relações Civil-Militares: o legado autoritário da constituição brasileira de 1988. In: TELES, Édson; SAFATLE, Vladimir (Org.). O que resta da ditadura: a exceção brasileira. São Paulo: Boitempo, 2010. p. 66 y ss. 
Sin prejuicio del reconocimiento de la implementación del acceso a los archivos por las vías jurídicas, la tesis que ahora se intenta plantear es que en Brasil no hubo rupturas de la identidad institucional, de forma tal que la juridificación del pasado parece no solucionar el tema de la manutención histórica de las estructuras de poder y de los mecanismos de reproducción del capital en el ámbito de la regulación institucional. Hasta ese punto me parece que la investigación de las posibilidades de un juicio de validez universal sobre la superación histórica del pasado mediante el derecho se confronta con sus límites. Para atravesar esos límites sería recomendable elevar al plano de la consciencia - incluso porque las experiencias totalitarias cuidan de una cierta "fragmentación de la consciencia" o "consciencia incompleta", porque todavía nos falta una síntesis histórica definitiva de las dictaduras latinoamericanas - (por eso es tan importante elevar al plano de la consciencia) y desarrollar la viabilización de una práctica determinación de esa consciencia, o sea, en nuestras vidas concretas, independiente de una mediación simbólica de los mecanismos jurídicos, agarrar la historia con nuestras propias manos y superar las estructuras autoritarias que afectan, sin embargo del floreo de lenguaje apelativo, la construcción de una Latinoamérica libre.

Les agradezco muchísimo y les dejo a todos mis sinceros agradecimientos, a esta Universidad de Mar del Plata, que tan afectivamente me invitó para participar del debate de un tema que dice tanto de nosotros mismos - y quizás puede ser una de las piedras fundamentales para la realización de la tan festejada hermandad latinoamericana. Muito obrigado.

Mar del Plata, fevereiro de 2011.

\section{Referencias}

AGUIAR, Flávio Wolf de. A tesoura e o quadro: uma visão sobre a censura à imprensa durante o regime de 1964. Margem Esquerda: Ensaios Marxistas, São Paulo, n. 3, p. 43-47, 2004.

ALARCON, Rodrigo. Brasil: represión y tortura. Santiago de Chile: Editorial Orbe, 1971.

ALMEIDA, Frederico Normanha Ribeiro. A nobreza togada: elites jurídicas e política da administração da justiça no Brasil. 2006. 329f. Tese (Doutorado)-Faculdade de Filosofia, Letras e Ciências Humanas, Universidade de São Paulo, São Paulo, 2006.

ALVES, Maria Helena Moreira. Estado e oposição no Brasil (1964-1984). São Paulo: Edusc, 2005.

AMARAL, Azevedo. O Estado autoritário e a realidade nacional. Rio de Janeiro: José Olympio, 1938. v. 1.

AMBOS, Kai. De la estructura 'jurídica' de la represión y de la superación del pasado en Argentina mediante el derecho penal: un comentario desde el punto de vista jurídico. Revista de Ciencias Penales, Montevideo, n. 3, p. 21-35, 1997. 
O marco jurídico da justiça de transição. Trad. Pablo Rodrigo Aflen da Silva. In: AMBOS, Kai; ZILLI, Marcos et al. (Org.). Anistia, justiça e impunidade: reflexões sobre a justiça de transição no Brasil. Belo Horizonte: Ed. Fórum, 2010.

APONTE CARDONA, Alejandro. La Colombia: un caso sui generis nell'ambito della giustizia di transizione. In: FRONZA, Emanuela; FORNASARI, Gabriele (Org.). Il superamento del passato e il superamento del presente: la punizione delle violazioni sistematiche dei diritti umani nell'esperienza argentina e colombiana. Trento: Universitá degli Studi di Trento, 2009.

ARENDT, Hannah. Eichmann em Jerusalém: um relato sobre a banalidade do mal. Trad. José Rubens Siqueira. 4. reimp. São Paulo: Cia. das Letras, 1999.

Responsibility and judgement. New York: Schocken Books, 2003.

The origins of totalitarism. San Diego: Harvest Book, 1976.

BATISTA, Nilo. Nota introdutória. In: DIMOULIS, Dimitri (Org.) Justiça de transição no Brasil. São Paulo: Saraiva, 2010. p. 14.

BERCOVICI, Gilberto. O direito constitucional passa, o direito administrativo permanece: a persistência da estrutura administrativa de 1967. In: TELES, Édson; SAFATLE, Vladimir (Org.). $O$ que resta da ditadura: a exceção brasileira. São Paulo: Boitempo, 2010.

CARVALHO, Carlos Eduardo. Governo Lula, o triunfo espetacular do neoliberalismo. Margem Esquerda: Ensaios Marxistas, São Paulo, n. 3, 2004.

CASTRO, Marcos de. A Igreja e o autoritarismo. Rio de Janeiro: Zahar, 1985.

CERVEIRA, Neusah Maria. Memória da dor: a Operação Condor no Brasil (1973-1985). São Paulo. 227f. Tese (Doutorado)-Faculdade de Filosofia, Letras e Ciências Humanas, Universidade de São Paulo, São Paulo, 2007.

COGGIOLA, Osvaldo. Governos militares na América Latina: a era das ditaduras Chile, Argentina e Brasil, luta armada e repressão. São Paulo: Contexto, 2001.

COMBLIN, Joseph. A ideologia da segurança nacional: o poder militar na América Latina. 3. ed. Rio de Janeiro: CIV Brasileira, 1980.

ROCHA, Maria Selma de Moraes. A evolução dos conceitos da doutrina da segurança nacional da escola superior de guerra nos anos 70. 1996. 177f. Dissertação (Mestrado)-Faculdade de Filosofia, Letras e Ciências Humanas, Universidade de São Paulo, São Paulo, 1996.

COSTA, Célia Maria Leite. O direito à informação nos arquivos brasileiros. In: FICO, Carlos et al. (Org.). Ditadura e democracia na América Latina: balanço histórico e perspectivas. Rio de Janeiro: FGV Editora, 2008.

DIMOULIS, Dimitri. Justiça de transição e função anistiante no Brasil: hipostasiações indevidas e caminhos de responsabilização. In: DIMOULIS, Dimitri (Org.). Justiça de transição no Brasil. São Paulo: Saraiva, 2010. 
DINGES, John. Os anos do Condor: uma década de terrorismo no Cone Sul. Trad. Rosaura Eichenberg. São Paulo: Cia. das Letras, 2005.

DINIZ, Eduardo Saad. A sociologia da decisão: a econômica, a política, a jurídica. Revista da Faculdade de Direito da Universidade de São Paulo, São Paulo, v. 102, p. 953-965, jan./dez. 2007.

DREIFUSS, René Armand. 1964: a conquista do Estado, ação política, poder e golpe de classe. 2. ed. Rio de Janeiro: Petrópolis, 1981.

EIROA, Pablo. Justicia, reconciliación y paz. Si y por qué castigar por medio de tribunales internacionales. In: PASTOR, Daniel R.; GUZMÁN, Nicolás (Org.). Problemas actuales de la parte general del derecho penal. Buenos Aires: Ah-Hoc, 2010.

FALCONE, Andrés. Superação do Passado Alemão pelo Direito Penal: Reflexões sobre os Vinte Anos da Queda do Muro de Berlim. Trad. Eduardo Saad-Diniz. In: Editora Magister, 07.01.2011, disponible en: <http://www.editoramagister.com/doutrina_ler.php?id=902>. Aceso en: 07 jan. 2011. FÁVERO, Eugênia Augusta Gonzaga. Crimes da ditadura: iniciativas do Ministério Público Federal em São Paulo. In: SOARES, Inês Virgínia Prado (Org.). Memória e verdade: a justiça de transição no Estado democrático brasileiro. Belo Horizonte: Ed. Fórum, 2009.

FERNANDES, Antonio de Pádua. A produção legal da ilegalidade: os direitos humanos e a cultura jurídica brasileira. 2005. 220f. Tese (Doutorado)-Faculdade de Direito, Universidade de São Paulo, São Paulo, 2005.

FERNANDES, Fernando. O processo penal como instrumento de política criminal. Coimbra: Almedina, 2001.

FERRAZ JUNIOR, Tercio Sampaio. Anistia: geral e irrestrita. Folha de S.Paulo, São Paulo, 16 ago. 2008. Opinião.

FON, Antonio Carlos. Tortura: a história da repressão política no Brasil. 3. ed. São Paulo: Global, 1979.

FRONZA, Emanuela. Profili penalistici del negazionismo. Rivista Italiana di Diritto e Procedura Penale, Milano, v. 42, n. 3, 1999.

FRONZA, Emanuela; FORNASARI, Gabriele. Premessa. In: FRONZA, Emanuela; FORNASARI, Gabriele (Org.). Il superamento del passato e il superamento del presente: la punizione delle violazioni sistematiche dei diritti umani nell'esperienza argentina e colombiana. Trento: Universitá degli Studi di Trento, 2009.

GABEIRA, Fernando. O que é isso companheiro? São Paulo: CODECRI, 1979.

GASPARI, Elio. A ditadura derrotada. São Paulo: Cia. das Letras, 2003. . A ditadura encurralada. São Paulo: Cia. das Letras, 2004. . A ditadura envergonhada. São Paulo: Cia. das Letras, 2002. 
A ditadura escancarada. São Paulo: Cia. das Letras, 2002.

GORENDER, Jacob. No 40 triste aniversário do triste evento de 1964: o golpismo contra a História. Margem Esquerda: Ensaios Marxistas, São Paulo, n. 3, 2004.

INFORMAÇÃO pública não é prioritária ao Planalto: divergências no governo explicam o desinteresse de Lula sobre o tema. Folha de S.Paulo, São Paulo, 05 dez. 2010. p. A-13.

JASPERS, Karl. Die Schuldfrage. Zurich: Artemis, 1946.

JORDÃO, Fernando. Dossiê Herzog: prisão, tortura e morte no Brasil. 2. ed. São Paulo: Global, 1979.

JUIZ internacional vê caminho para novas ações contra Anistia. Folha de S.Paulo, São Paulo, 16 dez. 2010. p. A-15.

KASTNER, Fatima. Das Welttheater des Pardons: zum Verhältnis von Recht, Vergebung und Gedächtnis. In: TEUBNER, Günther (Org.). Nach Jacques Derrida und Niklas Luhmann: zur (Un) Möglichkeit einer Gesellschaftstheorie der Gerechtigkeit. Stuttgart: Lucius \& Lucius, 2008. p. 153166.

KIM, Young Whan. Vergangenheitsbewaltigung durch das Strafrecht? Archiv fur Rechts und Sozialphilosophie, n. 4, v. 84, p. 505-516, 1998.

KIRCHHEIMER, Otto. Political Justice: the use of legal procedure for political ends. Princeton: Greenwood Press, 1961.

KISHI, Sandra Akemi Shimada. Direito à informação e à participação na Justiça de Transição. In: SOARES, Inês Virgínia Prado (Org.). Memória e verdade: a justiça de transição no Estado democrático brasileiro. Belo Horizonte: Ed. Fórum, 2009.

KODALLE, Klaus M. Verzeihung nach Wendezeiten? Jenaer Philosophische Vorträge und Studien, Erlangen, v. 12, 1994.

KUSHNIR, Beatriz. Cães de guarda: jornalistas e censores, do AI-5 à Constituição de 1988. São Paulo: Boitempo, 2004.

LAFER, Celso. A reconstrução histórica dos direitos humanos: um diálogo com o pensamento de Hannah Arendt. 5. reimpr. São Paulo: Cia. das Letras, 1998.

LAGOA, Ana. SNI, como nasceu, como funciona. São Paulo: Brasiliense, 1983.

LIEUWEN, Edwin. Militarismo e política na América Latina. In: LIEUWEN, Edwin et al. (Org.). Militarismo e politica na América Latina. Rio de Janeiro: Zahar Editores, 1964.

LÍSIAS, Ricardo. Dez fragmentos sobre a literatura contemporânea no Brasil e na Argentina ou de como os patetas sempre adoram o discurso do poder. In: TELES, Édson; SAFATLE, Vladimir (Org.). O que resta da ditadura: a exceção brasileira. São Paulo: Boitempo, 2010. 
LOLLINI, Andrea. Costituzionalismo e giustizia di transizione: il ruolo costituente della Comissione sudafricana verità e riconciliazione. Bologna: Il Mulino, 2005.

LLANO CIFUENTES, Rafael. Relações entre a Igreja e o Estado: a Igreja e o Estado à luz do Vaticano II, do código de direito canônico de 1983 e da Constituição brasileira de 1988. 2. ed. Rio de Janeiro: José Olympio, 1989.

MACHADO, Maíra Rocha. A internacionalização do direito penal: a gestão de problemas internacionais por meio do crime e da pena. São Paulo: Ed. 34 LTda., 2004.

MAMPAEY, Luc; SERFATI, Claude. Os grupos financeiros armamentistas e os mercados financeiros: rumo a um compromisso 'guerra sem limites'? In: CHESNAIS, François (Org.). A finança mundializada. São Paulo: Boitempo, 2005.

MARTINS, Antonio. Sobre direito, punição e verdade: reflexões acerca dos limites da argumentação jurídica. In: DIMOULIS, Dimitri (Org.). Justiça de transição no Brasil. São Paulo: Saraiva, 2010.

MARTINS, Luciano. A "liberalização" do regime autoritário no Brasil. In: O’DONNELL, Guillermo et al. (Org.). Transições do regime autoritário: América Latina. São Paulo: Vértice, 1988.

MELLO, Celso Antonio Bandeira de. Imprescritibilidade dos crimes de tortura. In: SOARES, Inês Virgínia Prado (Org.). Memória e verdade: a justiça de transição no Estado democrático brasileiro. Belo Horizonte: Ed. Fórum, 2009.

MENDES, Ricardo Antonio Souza. Anti-reformismo e a questão social no Brasil: o golpe de 1964. In: FREIXO, Adriano de; MUNTEAL FILHO, Oswaldo (Org.). A ditadura em debate: Estado e sociedade nos anos do autoritarismo. Rio de Janeiro: Contraponto, 2005.

MERKEL, Reinhard. Folter und Notwehr. In: PAWLIK, Michael; ZACZYK, Rainer (Org.). Festschrift für Günther Jakobs zum 70. Geburtstag: C. Heymanns, 2007.

MEZAROBBA, Glenda. O que é justiça de transição? Uma análise do conceito a partir do caso brasileiro. In: SOARES, Inês Virgínia Prado (Org.). Memória e verdade: a justiça de transição no Estado democrático brasileiro. Belo Horizonte: Ed. Fórum, 2009.

Um acerto de contas com o futuro: a anistia e suas conseqüências, um estudo do caso brasileiro. São Paulo: Humanitas, 2006.

NEUMANN, Franz. Democratic and authoritarian state: essays in political and legal theory. New York: The Free Press, 1957.

NEVES, Marcelo. A constitucionalização simbólica. 2. ed. São Paulo: WMG Martins Fontes, 2006.

O'DONNELL, Guillermo. Reflexões sobre os estados burocrático-autoritários. São Paulo: Vértice, 1987.

OLIVEIRA, João Roberto Pimenta. Princípio da publicidade, arquivos públicos e justiça de transição. In: SOARES, Inês Virgínia Prado (Org.). Memória e verdade: a justiça de transição no Estado democrático brasileiro. Belo Horizonte: Ed. Fórum, 2009. 
PADRÓS, Enrique Serra. Repressão e violência: segurança nacional e terror de Estado nas ditaduras latino-americanas. In: FICO, Carlos et al. (Org.). Ditadura e democracia na América Latina: balanço histórico e perspectivas. Rio de Janeiro: FGV Editora, 2008.

PASTOR, Daniel. Processi penali solo per conoscere la verità? L'esperienza argentina. In: FRONZA, Emanuela; FORNASARI, Gabriele (Org.). Il superamento del passato e il superamento del presente: la punizione delle violazioni sistematiche dei diritti umani nell'esperienza argentina e colombiana. Trento: Universitá degli Studi di Trento, 2009.

PAULANI, Leda. Brasil Delivery: servidão financeira e estado de emergência econômico. São Paulo: Boitempo, 2008.

PERRUSO, Camila Akemi. O desaparecimento forçado de pessoas no sistema interamericano de direitos humanos: direitos humanos e memória. 2010. 222f. Tese (Doutorado)-Faculdade de Direito, Universidade de São Paulo, São Paulo, 2010.

PIOVESAN, Flávia. Direito internacional dos direitos humanos e lei de anistia: o caso brasileiro. In: SOARES, Inês Virgínia Prado (Org.). Memória e verdade: a justiça de transição no Estado democrático brasileiro. Belo Horizonte: Ed. Fórum, 2009.

PYE, Lucien W. Os exércitos e o processo de modernização política. In: LIEUWEN, Edwin et al. (Org.). Militarismo e política na América Latina. Rio de Janeiro: Zahar, 1964.

RAGO FILHO, Antonio. Ideologia 64. 1998. 68f. Tese (Doutorado)-Pontificia Universidade Católica de São Paulo, São Paulo, 1998.

REALE JUNIOR, Miguel. Razão e subjetividade no direito penal. Ciências Penais, v. 00, p. 226$249,2004$.

RICOEUR, Paul. La mémoire, l'historie, l'oubli. Paris: Éditions du Seuil, 2000.

ROUQUiÉ, Alain. O Estado militar na América Latina. Trad. Leda Rita Cintra Ferraz. São Paulo: Alfa-Ômega, 1982.

SAFATLE, Vladimir. Do uso da violência contra o Estado ilegal. In: TELES, Édson; SAFATLE, Vladimir (Org.). O que resta da ditadura: a exceção brasileira. São Paulo: Boitempo, 2010.

SANCINETTI, Marcelo. Derechos humanos en la Argentina postdictatorial. Buenos Aires: Lerner Editores Asociados, 1998.

SANTOS, Lyndon de Araújo. O púlpito, a praça e o palanque: os evangélicos e o regime militar brasileiro. In: FREIXO, Adriano de; MUNTEAL FILHO, Oswaldo (Org.). A ditadura em debate: Estado e sociedade nos anos do autoritarismo. Rio de Janeiro: Contraponto, 2005.

SANTOS, Maria Guena dos. Operação Condor: uma conexão entre as políticas do Cone Sul da América Latina, em particular Brasil e Paraguai, durante a década de 70. 1998. 2v. Dissertação (Mestrado)-Faculdade de Filosofia, Letras e Ciências Humanas, Universidade de São Paulo, São Paulo, 1998. 
SANTOS, Roberto Lima. Crimes da ditadura militar: responsabilidade internacional do Estado brasileiro por violação aos direitos humanos. Porto Alegre: Núria Frabis Editora, 2010.

SCHMITT, Carl. Das internationalrechtliche Verbrechen des Angriffskrieges und der Grundsatz 'Nullum crimen, nulla poena sine lege'. Berlin: Duncker \& Humblot, 1994.

. Die Diktatur: von den Anfängen des modernen Souveränitätsgedankens bis zum proletarischen Klassenkampf. 7. ed. Berlin: Duncker \& Humblot, 2006.

SEBRIN, Kenneth P. Diálogos na sombra: bispos e militares, tortura e justiça social na ditadura. Trad. Carlos Eduardo Lins e Silva. São Paulo: Cia. das Letras, 2001.

SENRA, Álvaro de Oliveira. Após Geisel: crise do desenvolvimentismo e afirmação do neoliberalismo no Brasil. In: FREIXO, Adriano de; MUNTEAL FILHO, Oswaldo (Org.). A ditadura em debate: Estado e sociedade nos anos do autoritarismo. Rio de Janeiro: Contraponto, 2005.

SILVA, Fernando de Barros e. Ecos da ditadura. Folha de S.Paulo, São Paulo, 27 dez. 2010. p. A-2.

SOARES, Inês Virgínia Prado. Memoria democrática e desaparecidos políticos. In: SOARES, Inês Virgínia Prado (Org.). Memória e verdade: a justiça de transição no Estado democrático brasileiro. Belo Horizonte: Ed. Fórum, 2009.

SOUZA, Percival. Autopsia do medo: vida e morte do delegado Sérgio Paranhos Fleury. São Paulo: Globo, 2000.

STEPHANOU, Alexandre Ayub. Censura no regime militar e militarização das artes. Porto Alegre: Edipucrs, 2001.

SWENSSON JÜNIOR, Lauro Joppert. Punição para os crimes da ditadura militar: contornos do debate. In: DIMOULIS, Dimitri (Org.). Justiça de transição no Brasil. São Paulo: Saraiva, 2010.

TAVARES, André Ramos; AGRA, Walber de Moura. In: SOARES, Inês Virgínia Prado (Org.). Memória e verdade: a justiça de transição no Estado democrático brasileiro. Belo Horizonte, 2009.

TAVARES, Luiz Edmundo; FREIXO, Adriano de. O samba em tempo de ditadura: as transformações no universo das grandes escolas do Rio de Janeiro nas décadas de 1960 e 1970. In: FREIXO, Adriano de; MUNTEAL FILHO, Oswaldo (Org.). A ditadura em debate: Estado e sociedade nos anos do autoritarismo. Rio de Janeiro: Contraponto, 2005.

TELES, Édson; SAFATLE, Vladimir. Apresentação. In: TELES, Édson; SAFATLE, Vladimir (Org.). O que resta da ditadura: a exceção brasileira. São Paulo: Boitempo, 2010.

TEUBNER, Günther. Verrechtlichung: Begriff, Merkmale, Grenzen, Auswege. In: KÜBLER, Friedrich (Org.). Verrechtlichung von Wirtschaft, Arbeit und soziale Solidarität. Baden-Baden: Nomos, 1984. p. 289-344.

UESSLER, Rolf. A guerra como prestação de serviços: a destruição da democracia pelas empresas. Rio de Janeiro: Estação Liberdade, 2008. 
VALE, Osvaldo Trigueiro do. O Supremo Tribunal Federal e a instabilidade politico-institucional. Rio de Janeiro: Civilização Brasileira, 1976.

VALÉRIO, Otávio Lucas. A toga e a farda: o Supremo Tribunal Federal e o regime militar. 2010. 222f. Dissertação (Mestrado)-Faculdade de Direito, Universidade de São Paulo, São Paulo, 2010.

WEICHERT, Marlon Alberto. Responsabilidade internacional do Estado brasileiro na promoção da justiça transicional. In: SOARES, Inês Virgínia Prado (Org.). Memória e verdade: a justiça de transição no Estado democrático brasileiro. Belo Horizonte: Ed. Fórum, 2009.

WHITE, Hayden. Meta-história. São Paulo: Edusp, 1995.

ZAVERUCHA, Jorge. Relações Civil-Militares: o legado autoritário da constituição brasileira de 1988. In: TELES, Édson; SAFATLE, Vladimir (Org.) O que resta da ditadura: a exceção brasileira. São Paulo: Boitempo, 2010. 